Chapter 7

\title{
The Potential of Targeting LRRK2 in Parkinson's Disease
}

\author{
F.Y. Ho, K.E. Rosenbusch and A. Kortholt \\ Additional information is available at the end of the chapter \\ http://dx.doi.org/10.5772/57362
}

\section{Introduction}

Parkinson's disease (PD) is the second most common neurodegenerative disease that affects more than 5 million people, accounting to $1-2 \%$ of the population worldwide. It is characterized by the loss of dopaminergic neurons in the substantia nigra associated with the formation of fibrillar aggregates that are composed of $\alpha$-synuclein and other proteins [1]. PD is clinical characterized by four major symptoms; tremor, bradykinesia, rigidity and postural instability. Initially PD was considered sporadic, however genetic studies in patients families revealed mutations that are segregating with PD. Nowadays, in addition to environmental factors, mutations within 6 loci (SNCA, LRRK2, PRKN, DJ1, PINK1 and ATP13A2) have been clearly demonstrated to be causative to familial PD [2-4]. Among them, SNCA and LRRK2 mutations cause autosomal dominant forms of PD [5]. Human leucine-rich-repeat kinase 2 (LRRK2) has been found to be thus far the most frequent cause of late-onset PD [6, 7]. The identification of missense mutations in LRRK2 has redefined the role of genetic variation in PD susceptibility. The mutations are found in 5-6\% of patients with familial PD, and also have been implicated with sporadic PD [8]. LRRK2 mutations initiate a penetrant phenotype with complete clinical and neurochemical overlap with idiopathic PD (IPD). Penetrance is age-related, around $75 \%$ mutation carriers showed PD symptoms at the age of $80[9,10]$. Tremor is more commonly observed in LRRK2 mediated PD compared to IPD [11]. Although dementia and cognitive defects are not frequently present in patients with mutations in LRRK2, LRRK2 does associate with Lewy bodies in IPD and dementia [12-14].

LRRK2 belongs to the Roco family of proteins, which constitute a novel family of Ras-like Gproteins that have an unique domain architecture [15]. LRRK2 is a large and complex protein with multiple domains; Armadillo repeats (ARM), Ankyrin repeats (ANK), leucine-rich repeats (LRR), a Ras of complex (Roc), a C-terminal of Roc (COR), kinase domain and WD40 repeats (Fig. 1). Most of the PD mutations are accumulated around the central core of the protein, one is found in the LRR, two in the Roc domain (with multiple substitutions), one in 


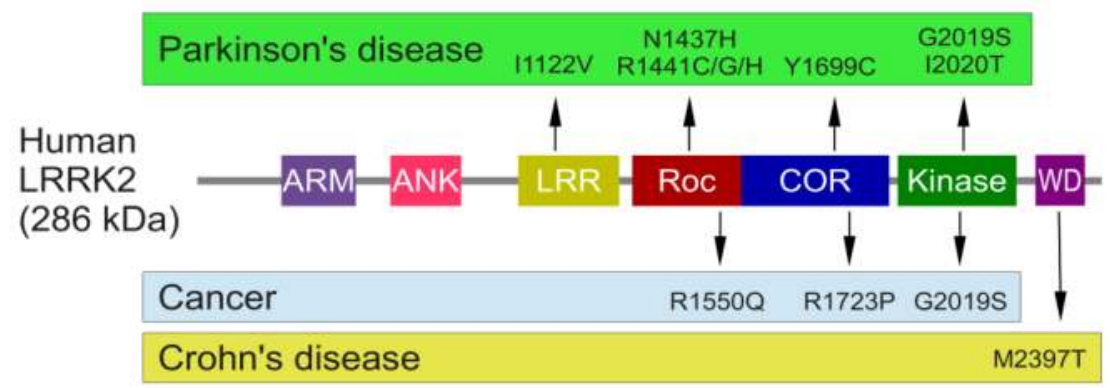

Figure 1. Domain topology of human LRRK2. The labels show the segregating mutations of LRRK2 in Parkinson's disease (green box), cancer associated mutations (blue box) and Crohn's disease (yellow box).

the COR and two in the kinase domain [16, 17]. The multiple disease-linked mutations in LRRK2 represent a unique opportunity to explore the activation mechanism of the protein and its miss-regulation in PD. In this chapter we will focus on the effects of LRRK2 on cellular signalling, the recent progress in elucidating the activation mechanism and discuss possible ways to therapeutically target LRRK2 mediated PD.

\section{Cellular function of LRRK2}

Although several potential LRRK2 mediated pathways and interaction partners have been identified, yet much about the cellular functions of LRRK2 and LRRK2 mediated progression of PD remains unknown [17]. Below we highlight the evidence for a role of LRRK2 in a wide variety of these cellular pathways and discuss a possible link to other PD-related genes.

\subsection{Neurite development, outgrowth and branching}

LRRK2 is directly linked to neurite outgrowth. Several studies have shown that primary neurons over-expressing mutant LRRK2 have significantly reduced neurite outgrowth and branching. However, the reported reduction varies and might only be significant in long term culture [18-20]. Adult neurogenesis and neurite outgrowth is impaired in mice overexpressing G2019S LRRK2 in the subventricular zone (SVZ) and hipppocampal denate gyrus [21]. This deficiency of neurite outgrowth can be rescued by inhibiting LRRK2 kinase activity with nonspecific or more specific LRRK2 inhibitors, such as staurosporin [20] or G1023 [22], respectively. A recent study analysed LRRK2 expression in neonatal and postnatal mouse embryo and showed that LRRK2 expression can be detected in E10.5 of neural tissue. At the time of neurogenesis, prominent expression is found in the ventricular and SVZ of the telencephalon [23]. LRRK2 is also expressed in adult SVZ, where neural stem cells generate neurons in adult brain [24]. Both R1441G and G2019S LRRK2 impair development of neural stem cells [25-27], whereas LRRK2 deficient cells have increased neurite development [25, 28, 29]. Although the 
mechanisms are yet to be identified, these data show that LRRK2 is regulating neurite-, and neural development. Interestingly, LRRK2 is not only controlling neurite development via its kinase activity, also the LRRK2 G-domain and protein-protein interaction domains play a direct and important role. Tubulin, ArfGAP1, Rac1 and DVL family proteins bind to and/or are regulated by the G domain of LRRK2 and subsequently modulate the cytoskeleton [30-34]. Wnt signalling is essential for several steps in neural development, including presynaptic assembly, signal transduction at the postsynaptic cleft and adult neurogenesis [35, 36]. Overexpression of Wnt7a or inhibition of the Wnt signalling suppressor GSK3 $\beta$ promotes neuron differentiation and maturation $[37,38]$. LRRK2 interacts with both the Wnt co-receptor low-density lipoprotein receptor-related protein 6 (LRP6) and the downstream DVL proteins, suggesting that LRRK2 might function as a scaffold for Wnt signalling proteins [39].

\subsection{Autophagy}

It is generally accepted that neurodegenerative diseases are associated with dysregulation of autophagy [40]. Autophagy is the regulated self-degradation of damaged organelle, ubiquitinated proteins and protein aggregates by lysosomes. Autophagy is an adaptive response which is stimulated by stress or unfavourable conditions, such as starvation, accumulation of aggregate-prone proteins, oxidative stress, and infection [41]. Autophagy is a double-edged sword; it can promote cell survival or lead to cell death [42]. Autophagy regulates the removal of protein aggregates, which are a common symptom in neurodegenerative diseases, and thereby promotes cell survival [43-45]. Protein aggregates such as $\alpha$-synuclein [46], tau [47], and huntingtin [48] are cleared by autophagy. Disruption of the autophagy related genes atg5 or $a t g 7$ in mice, results in severe impairment autophagy and neurodegeneration $[49,50]$. The purkinje cells of the mutant mice are characterized by axonal dystrophic swelling and degenerate within a few weeks after birth [51, 52]. Mice with conditional knockdown of atg7 gene in the substantia nigra and cerebellum showed age-related loss of dopaminergic neurons and autophagy deficiency dependent accumulation of alpha-synuclein aggregates [53]. Expression of LRRK2 G2019S in retinoic acid differentiating SH-SY5Y neuroblastoma cells results in the accumulation of LRRK2 containing-autophagic vacuoles and shortens neuritic processes. Cells expressing wild-type LRRK2 show a similar but less severe phenotype. Disruption of $a t g 7$ and microtubule-associated protein 1A/1B-light chain 3 (lc3) in these LRRK2 mutants completely rescues the phenotype [54]. Co-localization of LRRK2 with p62 and LC3 puncta in autophagic vacuoles is reported for human brain and by several other cell culture studies [55]. Not only overexpression of wildtype and mutant LRRK2 increases accumulation of autophagic vacuoles and the induction of autophagy [56-58], also knocking down LRRK2 activity by either RNAi or with specific LRRK2 inhibitors stimulates autophagy [59]. In addition, LRRK2 activity itself is regulated by macroautophagy and chaperon-mediated autophagy (CMA). LRRK2 inhibits CMA and hinders clearance of $\alpha$-synuclein by CMA [60]. The complex role of LRRK2 in autophagy is not only playing a role in Parkinson's disease but has been linked to several other diseases as well (see below). 


\subsection{Mitochondrial disease}

Mitochondrial dysfunction in the pathogenesis of PD has been studied extensively. Although the cellular mechanism remains largely unclear, LRRK2 seems to be important for proper mitochondrial regulation. Some reports suggest that LRRK2 partly localizes in mitochondria and several LRRK2 PD associated mutations results in impaired mitochondrial function [61]. Cells carrying the LRRK2 G2019S mutation display a general uncoupling of the oxidative phosphorylation [62]. The mitochondrial potential and intracellular ATP levels are reduced along with increased oxygen utilization [62]. Also shape and organization of the mitochondria are significantly affected as they appear elongated with an enhanced interconnectivity [63]. The increased kinase activity of LRRK2 G2019S leads to an increased AMP- activated protein kinase (AMPK) level [57]. Since, AMPK is an autophagy regulating protein, its enhanced activity results in an increased number of autophagosomes [57]. High levels of autophagy/ autophagic vacuoles lead, as described above, to a vulnerability and thus retraction and degeneration of neurons, one of the main characteristic features of PD [54]. Several other PD associated proteins, including $\alpha$-synuclein, Parkin, DJ- 1, PINK1 and HTRA2 [64-66], show similar defects in mitochondria regulation, suggesting that LRRK2 and other PD associated proteins share common pathogenic pathways.

\subsection{Common pathways for LRRK2 and other PD-relelated proteins?}

Lewy bodies are protein aggregates found in degenerating dopaminergic neurons of PD patients. They are composed of many different proteins, including LRRK2 and $\alpha$-synuclein $[67,68] . \alpha$-synuclein is a small protein (140 amino acids) that is located in presynaptic nerve terminal vesicles, plasma membrane lipid rafts and the nucleus [69-71]. Recent studies show that $\alpha$-synuclein promotes SNARE-complex assembly [72, 73], and either overexpression or aggregation of $\alpha$-synuclein interferes with vesicular trafficking [74-76]. Phosphorylation of $\alpha$ synuclein is critical for aggregation and pathology. Since phosphorylation of $\alpha$-synuclein serine residue 129 in HEK293T expressing LRRK2 is increased, it was initially proposed that $\alpha$-synuclein is a direct substrate of LRRK2 [77]. However, phosphorylation of $\alpha$-synuclein is normal in LRRK2 ${ }^{-/}$mice [78], suggesting that the rather weak effect of LRRK2 on $\alpha$-synuclein S129 phosphorylation in cells is most likely indirect. Expression of LRRK2 and $\alpha$-synuclein is co-regulated; increase of $\alpha$-synuclein in mouse striatum results in increased LRRK2 transcription [79]. Both LRRK2 and $\alpha$-synuclein interact with Rab5, which is important for vesicle trafficking [80, 81], suggesting LRRK2 and $\alpha$-synuclein might share common pathways. Recessive mutations of Parkin, PINK1 and DJ-1 are causative to PD [82]. PTEN-induced kinase 1 (PINK1) is important for mitochondrial function and its deletion leads to increased susceptibility to oxidative stress $[83,84]$. PINK1 is a cytosolic serine/threonine kinase under steadystate condition and its mitochondrial localization is stabilized by decreased mitochondrial membrane potential, an indicator of damaged mitochondria [85]. Parkin is an E3 ubiquitin ligase, which is phosphorylated and recruited to mitochondria by PINK1. The activated Parkin and PINK1 in conjugation clear damaged mitochondria via selective degradation and autophagy [85]. Co-expression of Parkin and LRRK2 G2019S in flies protects rotenone-induced neurodegeneration of dopaminergic neurons [86]. Expression of LRRK2 PD mutants in pink1- 
null flies enhances the phenotype [87]. In human cells, LRRK2 is found to interact with Parkin, and co-expression of the two proteins increases LRRK2 containing aggregates. Altogether, this suggests that LRRK2 and PINK1/Parkin pathway are using similar pathways for the regulation of mitochondrial function. DJ-1 is a redox sensitive protein that is linked to a large variety of function, for example Ras-dependent cell transformation, neuroprotection, transcription, apoptosis suppression, P53 signalling, chaperon and protease [88]. It protects neurons from oxidative stress, by scavenging mitochondrial peroxide through oxidation of cysteine residues, and by binding metal ions like mercury and copper [89]. In cells that are exposed to oxidizing agents and mouse brains treated with rotenone, DJ-1 converts to more acidic isoforms [90, 91]. DJ-1 deficient cells, including cell lines and primary neurons, display altered mitochondrial morphology and an increase in autophagic flux [92]. PINK1 and Parkin overexpression can rescue the mitochondrial morphology of $d j$-1-null cells, but vice versa DJ-1 cannot rescue the defects of PINK1 and Parkin mutants. However, DJ-1 can protect PINK1 deficient neurons from oxidative stress induced by rotenone, suggesting DJ-1 may act both upstream and parallel to the PINK1/Parkin pathway [93]. In comparison to PINK1/Parkin, LRRK2 shows a less direct relation with DJ-1, albeit it still clearly exacerbate the eye phenotype of DJ-1 overexpression / loss in Drosophila [87]. As described previously, LRRK2 is important for autophagy in neurons, thus it is tempting to speculate that LRRK2 plays a role together with PINK1/Parkin and DJ-1 in regulating mitochondrial homeostasis.

\subsection{LRRK2 and other diseases}

Mutations in LRRK2 have been linked to several other diseases, including Crohn's disease and cancer. Carriers of LRRK2 G2019S mutation have an increased risk of non-skin cancer [94, 95]. Knock-down of LRRK2 in different cancer cell lines by RNAi, results in decreased stability of the $4 \mathrm{E}-\mathrm{BP} 1$ protein [96]. Stability of 4E-BP1 protein is dependent on its phosphorylation state; it is a known downstream target of mTOR, inhibition of mTOR leads to accumulation of dephosphorylated 4E-BP and blocks cell transformation in a Kaposi's sarcoma model [97]. The $\mathrm{PI} 3 \mathrm{~K} / \mathrm{mTOR}$ pathway is very frequently dysregulated in human cancer [98]. Previously, 4E$\mathrm{BP}$ was identified as a direct LRRK2 kinase substrate (see section 3.3), suggesting LRRK2 might play a role in regulating $4 \mathrm{E}-\mathrm{BP}$ stability and thus the oncogenic PI3K/mTOR pathway.

Genome wide association studies linked LRRK2 mutations to Crohn's disease (CD) and leprosy [99, 100]. CD associated mutations in the LRRK2 locus are located in non-coding regions, with an exception of the polymorphism rs3761863, which is leading to M2397T substitution in the WD40 repeats of LRRK2 [99]. CD is a chronic inflammatory disorder which primarily affects the gastrointestinal tract. Patients with $C D$ have defective macrophages and neutrophils, resulting in a deficient innate immunity [101, 102]. LRRK2 is widely expressed in many organs and tissue, including brain, kidney and spleen. In the spleen, LRRK2 is highly expressed in $\mathrm{CD} 19^{+} \mathrm{B}$ cells, whereas lower expression was detected in CD4 ${ }^{+}$or CD8 ${ }^{+} \mathrm{T}$-cells, macrophages, and monocytes [103, 104]. In macrophages, LRRK2 expression is induced by activation of Toll-like receptors and viral transduction [103]. CD patients exhibit high concentrations of proinflammatory cytokines, including interferon- $\gamma($ IFN- $\gamma)$, which induces LRRK2 expression in macrophages [105]. In cell-based reporter studies, LRRK2 is found to activate 
NFkB and inhibit NFAT, which both are important transcription factors in the immune system $[103,106]$. Interestingly this effect is independent of LRRK2 kinase activity, since expression of both wildtype and kinase dead LRRK2 result in a similar phenotype.

\section{Intramolecular LRRK2 activation mechanism}

LRRK2 has two bona-fide enzymatic activities from its Roc and kinase domain. It has been shown that both a functional Roc G-domain and kinase are essential for the pathogenicity of LRRK2. Importantly, several of the pathogenic mutations in LRRK2 result in decreased GTPase activity and enhanced kinase activity, suggesting a possible PD-related gain of abnormal function [107-109]. However the exact molecular mechanisms by which these mutations enhance LRRK2 catalytic activity are not completely resolved so far. Because of the lack of sufficient high quality recombinant LRRK2 protein, important understanding of the complex regulatory mechanism of LRRK2 has come from work with related Roco family proteins.

\subsection{Homologous Roco proteins as model to study the mechanism of LRRK2 mediated PD}

Roco proteins constitute a novel family of complex Ras-like GTPases that have an unique domain architecture [15]. Roco proteins are characterized by the presence of a Ras-like Guanine nucleotide binding domain, called Roc (Ras of complex proteins), followed by a COR domain (C-terminal of Roc), a conserved stretch of 300-400 amino-acids with no significant homology to other described protein domains (Fig. 2). The Roc and COR domains always occurs as a pair and so far no proteins are identified containing either the Roc or COR domain alone, suggesting that these two domains might function as one inseparable unit. Roco proteins were first identified in the social amoeba Dictyostelium discoideum and are found in prokaryotes, plants and metazoa, but not in Plasmodium and yeast. Based on domain topology, the family of Roco proteins can be divided into three groups, each containing at least one mammalian member. The first group is found in mammals (MASL1), plants and in prokaryotes. These proteins contain besides a Roc and COR domain always a N-terminal stretch of leucine-rich repeats (LRR), which are supposed to be involved in protein-protein interaction. The second group of Roco proteins is present in Dictyostelium and metazoa. In these proteins the Roc domain is again preceded by LRRs and the COR domain always succeeded by a kinase domain of the MAPKKK subfamily of kinases. A subset of Roco proteins contains the metazoan tumour suppressor death-associated protein kinases (DapK) domain, which is found in many proteins with apoptotic function [110]. Although there is a high variation in additional regulatory domains among the Roco proteins, previous studies have shown that the function and regulation of the catalytic core is conserved.

\subsection{Dictyostelium Roco proteins to study the LRRK2 activation mechanism}

Dictyostelium discoideum is a social, soil- dwelling amoeba that feeds on bacteria. The organism is genetically tractable with the ease of making gene disruptions and inducible expression, and at the same time it can be grown to large quantities for biochemical analyses [111]. Most 
Group 1 (in Prokaryotes, Plants and Metazoa)
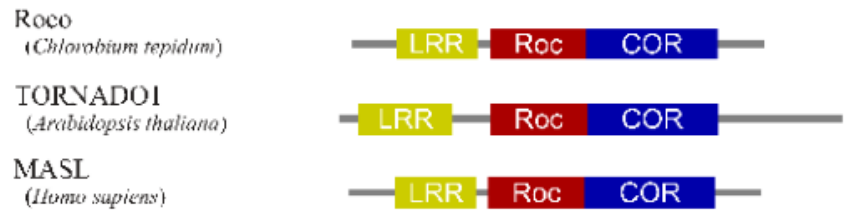

Group 2 (in Metazoa, Dictyostelium discoideum)

Homo sapiens

I.RRK 1
LRRK2 ANK

\section{Group 3 (in Metazoa)}

DAPK

(IIomo supiens)

- Kinase - ANK - Rog COR DD-

Figure 2. Domain architecture of the Roco family of proteins. The domains are leucine-rich repeat (LRR), Ras in complex domain (Roc), C-terminal of Roc domain (COR), ankyrin repeat (ANK), Kinase domain (Kinase), WD40 repeats (WD), armadillo repeat (ARM), Rho guanine nucleotide exchange factor domain (RhoGEF), Pleckstrin domain (PH), Dishevelled, Egl-10 and Pleckstrin domain (DEP), Rho GTPase activating protein domain (RhoGAP), Kelch motif (K), regulator of $\mathrm{G}$ protein signalling domain (RGS), N-terminal motif of RasGEF (N-GEF), Ras guanine nucleotide exchange factor domain (RasGEF), cyclic nucleotide binding domain (cNB), glucosyltransferases, Rab-like GTPase activators and myotubularins domain (GRAM), N-terminal myotubulin-related domain (myotub), protein tyrosine phosphatase domain (PTP) and death domain (DD). 

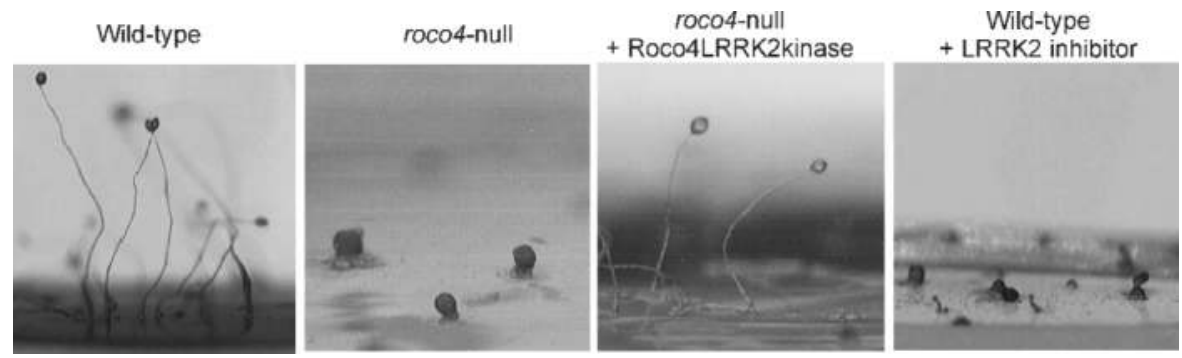

Figure 3. LRRK2 function and inhibition experiment with Dictyostelium cells. Wild-type, roco4-null and roco4-null cells expressing Roco4-LRRK2 kinase in which the kinase domain of Roco4 has been replaced with the kinase domain of LRRK2, were allowed to develop for 48 hours on nutrient-free agar. Pieces of agar were excised and photographed from the side. roco4-null cells fail to make a normal fruiting body due to defective synthesis of cellulose. The right panel shows a side view of the development of wild-type cells in the presence of the LRRK2-inhibitor H1152. Cells in the presence of $0.5 \mathrm{mM} \mathrm{H} 1152$ have the typical roco4-null phenotype. Figure modified with permission from Proc. Natl. Acad. Sci. USA, (Gilsbach et al., 2012).

importantly, many key pathways are conserved between Dictyostelium and human. Therefore, Dictyostelium offers unique advantages for studying fundamental cellular processes, as well as the molecular causes of human diseases [112]. Although Dictyostelium neither has a brain nor muscle, it is, as described below, an excellent model to study the molecular basis of LRRK2mediated PD.

Dictyostelium contains eleven Roco family members, that all belong to the second subgroup of the Roco family. They are sharing the characteristic Roc, COR and kinase domains and in addition most also have LRR (Fig. 2, [15]). Dictyostelium Roco proteins are structurally more varied than the Roco proteins found in all the other species together; various domains are additionally fused to the conserved region. Roco proteins are most likely the result of recent gene duplications, and are very homologous to mammalian LRRK2 [113]. Disruption of Dictyostelium Roco genes leads to very different phenotypes, indicating that they are involved in multiple cellular processes. They participate in processes as diverse as chemotaxis, cell division, osmotic-stress-response and development [114]. The strong and diverse phenotypes of the Dictyostelium Roco disruption mutants therefore provide a strong tool to investigate the activation mechanisms of Roco proteins. Especially the studies with Dictyostelium Roco4 gave mechanistic insight into the regulation of LRRK2 [114, 115]. Dictyostelium Roco4 has the same domain architecture as LRRK2, but in contrast to LRRK2, Roco4 is biochemically and structurally more tractable [115]. Roco4 plays an important role in the late development stage of Dictyostelium [114]. During the vegetative growth stage, single Dictyostelium cells feed on bacteria and divide by simple mitotic divisions. In times of starvation, a developmental program is initiated, which is accompanied by major changes in gene expression. As a result, single cells are able to form aggregates via cAMP- dependent chemotaxis, resulting in the development of mobile multicellular forms, called slugs [111]. Eventually, the slugs will permanently settle down, culminate and generate fruiting bodies, which consist of a cellulose containing stalk and basal disc and end in a spore head [116]. Single cell amoebae are embedded in the spore head, which are resistant to extreme temperatures or drought and can be 
released upon germination under more favourable environmental conditions [111]. Cells lacking roco4 undergo the characteristic streaming, aggregating and mound forming phases, however after 12 hours of starvation the cells start to display severe developmental defects. The formation of slugs and subsequent stalks and spore heads is severely delayed; 72 hours in the mutant cells, compared to 24 hours in wild-type [114]. Furthermore, roco4-null cells display aberrant fruiting body morphology as the spore heads are located on the agar surface due to a reduced cellulose level and thus instable stalks (Fig. 3, second panel). The strong developmental phenotype of roco4-null cells was used to determine essential structural elements in the protein. Remarkably, this phenotype can completely be rescued by expression of a chimeric Roco4 protein, in which its kinase domain has been replaced with the LRRK2 domain (Fig. 3, third panel) [115]. Furthermore, Roco4 kinase activity is inhibited by LRRK2 inhibitors (Fig. 3, right panel), and LRRK2 phosphorylates specific developed artificial substrates for LRRK2 in vitro [115, 117]. This shows that Roco4 has properties very much resembling those described for LRRK2, indicating that Roco4 protein thus can serve as a valid model to understand the complex structure and regulatory mechanism of LRRK2.

\subsection{LRRK2 kinase activity}

Protein kinases catalyze the transfer of $\gamma$-phosphate of ATP to the hydroxyl group of serine/ threonine/tyrosine in peptide substrates. Due to the simplicity, stability, and reversibility, protein phosphorylation is chosen by nature for modulating protein functions. Phosphorylation allows specific and dedicated control over enzymatic activities, regulation of protein localization and the transition between the ordered and disordered states of proteins [118]. Therefore, protein kinases are essential for many biological processes such as energy metabolism, cell cycle progression, transcription and cytoskeleton rearrangement. There are more than 500 protein kinases identified in the human genome, of which the majority are serine/ threonine kinases, a much smaller amount is tyrosine specific and a trace amount are atypical kinases [119].

LRRK2 kinase activity is extensively studied since its discovery, and it is found to be essential for neuronal toxicity induced by PD mutant of LRRK2 [120, 121]. LRRK2 and Roco proteins are serine/threonine specific kinases. Previously the structures of Roco4 kinase wild-type and the PD-related mutants G1179S and L1180T (G2019S and I2020T in LRRK2) were solved [115]. Like almost all kinases, Roco4 consists of a canonical, two-lobed kinase structure, with an adenine nucleotide located in the conventional nucleotide binding site [118, 122]. The Nterminal lobe is smaller, which is composed of an anti-parallel $\beta$-sheet and the large conserved $\alpha \mathrm{C}$-helix. It is followed by a linker connecting the larger C-terminal lobe, which is composed predominantly of $\alpha$-helices and is containing the activation loop with the conserved DFG motif at the N-terminus [115]. The ATP binding pocket is located between the $\mathrm{N}$ - and C-terminal lobes and forms together with the activation segment and $\alpha \mathrm{C}$-helix the catalytic site of the kinase. In its inactive (dephosphorylated) form, the activation segment of Roco4 is disordered, and not visible in the crystal structure. In the active (phosphorylated) conformation, the $\alpha \mathrm{C}$ helix is ordered and packs against the N-terminal lobe. This conformational change between the active and inactive conformation is conserved between most kinases, and often dependent 
on autophosphorylation of the activation loop [118, 122-124]. In vitro kinase and in vivo rescue experiments showed that Roco4 S1187 and S1189 are essential for regulating Roco4 kinase activity. Autophosphorylation is well demonstrated in LRRK2 by numerous studies. LRRK2 contains with T2031/S2032/T2035 three potential phosphorylation sites in the activation loop. Studies using phosphospecific antibodies have shown that all three sites are phosphorylated, but like for Roco4, only the two later sites, S2032 and T2035, are important for LRRK2 activity in vivo [125]. Most other autophosphorylation sites are located in the Roc domain and kinase domain, such as S1292, T1348, T1349, T1357, T1503, T1967, T1969 [22, 126, 127]. Mutations of these residues significantly affect the enzymatic activities of LRRK2. Importantly, mutating S1292 to alanine [22] or inhibiting kinase activity with inhibitors, completely rescues neurite outgrowth in LRRK2 PD mutants. This suggests that LRRK2 kinase activity is important for both the intramolecular activation mechanism, as well, for downstream signalling. Several putative LRRK2 kinase substrates have been identified so far. LRRK2 phosphorylates 4E-BP [128] and FoxO and thereby modulates their translation and transcription activities. However, the relevance of 4E-BP phosphorylation by LRRK2 for the progression in PD is still under debate [129-131]. Phosphorylation of FoxO induces expression of the pro-apoptotic Bcl-2 protein, Bim, and the endogenous caspase- 8 inhibitor, c-FLIP, leading to programmed cell death [132-134]. Therefore, FoxO may be one of the missing links between LRRK2 and cell death in neurons. [135]. Several LRRK2 substrates are linked to cytoskeleton remodelling; moesin promotes actin rearrangement in neurons [136, 137], and $\beta$-tubulin and tubulinassociated tau are important for neurite outgrowth and axonal transport [138-140].

\subsection{Mechanism of increased kinase activity in LRRK2 PD mutants}

The most prevalent PD mutation in the kinase domain is G2019S, which enhances kinase activity, while the PD-related mutation I2020T shows a slightly decreased activity [108, 109, 117, 121, 141]. Recently the molecular mechanism by which the G2019S mutation enhances LRRK2 was resolved using Dictyostelium Roco4. The LRRK2 G2019 and I2020 residues are conserved in Dictyostelium Roco4 and correspond to G1179 and L1180, respectively. Overlay of the solved Roco4 wild-type and the Roco4 G1179S structure didn't show large differences in the overall structure, however closer observation revealed that S1179 makes a new hydrogen bond with R1077, thereby presumably stabilizing the activation loop and the $\alpha \mathrm{C}$-helix in their active conformation. R1077 is conserved in almost all Roco proteins and corresponds to LRRK2 R1918. Kinase activity measurement with the Roco4 double mutant G1179S/R1077A and the homologous LRRK2 double mutant G2019S/R1918A, in which the new hydrogen bond is no longer possible, confirmed the proposed mechanism since it shows wild type kinase activity [115].

The structure of the PD-related mutant L1180T showed that the T1180 side-chain points into the solvent and revealed that it is most likely not directly involved in regulating kinase activity. Importantly, the data show that the PD-related effect of LRRK2 mutations result from different defects in the LRRK2 activation mechanism and suggest that different LRRK2 mutations such as S2019 and T2020 might require different ways of inhibition for the purpose of drug development $[115,142]$. 


\subsection{The RocCOR tandem}

The Roc domain of LRRK2 belongs to the family of small G-proteins. G-proteins are GTP binding proteins which switch between an active GTP- and inactive GDP-bound state. The G-domain has an universal switch mechanism that carries out the basic function of nucleotide binding and hydrolysis [143]. The universal switch mechanism between the inactive GDP and active GTP form often consist of only small structural changes in the so called switch regions [144]. Although, the two nucleotide-bound states have only a slightly different conformation, only the GTPbound conformation possesses high affinity for effector proteins [145]. In Roco family members the G-domain always occurs in tandem with the COR domain. Studies with both LRRK2 and Dictyostelium Roco4 revealed that a functional Roc domain is essential for kinase activity, the COR domain functions as the dimerization device and disruption of Roc or the kinase domain by a single point mutation leads to the complete inactivation of the protein. These suggest that the Roc-COR tandem is regulating kinase activity and/or that the kinase is regulating the activity of Roc by autophosphorylation [146]. The cycle of "classical" small G-protein is strictly controlled by GEFs (Guanine nucleotide Exchange Factors), which catalyze the exchange from GDP to GTP, and the intrinsic low GTP hydrolysis rate is increased by GAPs (GTPase Activating Proteins) [147]. It is well established that LRRK2 and other Roco proteins are active as a dimer ([148-150], see also below). The previously solved structure of the Roco protein from the bacteria Chlorobium tepidum, revealed that COR is the dimerization device and that Roco proteins, including LRRK2, belong to the GAD class of molecular switches (G proteins activated by nucleotide dependent dimerization) $[149,151]$. This class also includes proteins such as signal recognition particle, dynamin and septins [151]. It is proposed that the juxtaposition of the G domains of two monomers in the complex across the GTP-binding sites activates the GTPase reaction and thereby regulates the biological function of these proteins (Fig. 4). Since GTPase activity is regulated within the dimer complex, GTP hydrolysis by Roco proteins is not regulated by GAP's. LRRK2 and Roco proteins have a much lower affinity ( $\mu \mathrm{M}$ range) compared to other small G-proteins (nM range), and therefore most likely do not need GEFs for activation [149, 152]. The PD-related mutations, R1441C/G/Hin the Roc domain and $Y 1699 \mathrm{C}$ in the COR domain, do not affect nucleotide binding, but significantly decrease GTPase activity [153, 154]. Importantly, the structure of the Chlorobium tepidum Roco protein showed that the PD-analogous mutations of the Roc and COR domain are in close proximity to each other at the dimer interface. Furthermore, these mutations are present in a region of the protein that is strongly conserved between bacteria, Dictyostelium and man. PD-mutations in the Chlorobium tepidum protein, like that of LRRK2, decrease the GTPase reaction, most likely due to altered interaction in the dimer between the Roc and COR domains [149].

\subsection{Function of the N-terminus of LRRK2}

The N-terminal part of LRRK2 consists of Armadillo repeats (ARM), Ankyrin repeats (ANK), and leucine-rich repeats (LRR) (Fig. 1). All these domains are commonly found in signalling proteins, in which they have a role in protein-protein interaction or assembly of large protein complexes [155]. The N-terminal segment of LRRK2 is most likely involved in regulating activity and/or localization. ARM are approximately 40 amino acid long tandem repeated 
sequences that form superhelix of helices. ANK consist of seven structural repeats, each repeat forms two anti-parallel helices ending with a loop or hairpin [156, 157]. LRR are defined by an 11 amino acid long consensus sequence LxxLxLxxNxL, where leucine can be replaced by isoleucine, valine or phenylalanine [155]. The LRRK2 LRR domain is composed of 13 repeats, allowing the formation of its characteristic horseshoe shaped structure due to parallel lining $\beta$ - sheets with ending $\alpha$ - helices [139, 158, 159]. The LRR domain of LRRK2, and Dictyostelium Roco4, are not involved in Roc or kinase activation in vitro, but are absolutely essential for activity of the protein in vivo [160,161]. Recent data suggest that the LRR are directly involved in determining input/output specificity of the Roco proteins, most likely by binding upstream proteins that activate specifically the Roco protein and/or by selectively binding of the substrate (AK unpublished data). Previously, it has been shown that 14-3-3 proteins bind to the N-terminus of LRRK2 [25]. 14-3-3 are highly conserved proteins that have been found in a variety of organisms, including mammals, plants, yeast, Drosophila, and Dictyostelium [162, 163]. In human, the 14-3-3 protein family consists of 7 structural similar yet distinct isoforms: $\alpha, \beta, \gamma, \delta, \varepsilon, \zeta, \eta[162]$. The proteins exist as homo- or functional active heterodimers and are important for various signalling pathways, including neurotransmitter synthesis in mammalian brain tissue, via direct ligand binding [163, 164]. Interaction of 14-3-3 with LRRK2 is dependent on the phosphorylation of two conserved serine residues (S910, S935), situated at the N- terminal part of LRRK2 anterior to the LRR domain [158]. Since several LRRK2 specific kinase inhibitors abolish 14-3-3 binding, it is proposed that the binding is regulated by autophosphorylation $[165,166]$. However, other studies suggest that LRRK2 interaction is dependent on a so far unidentified upstream kinase [167]. Disrupted phosphorylation of the serine residues results in strong defects in LRRK2 signalling; the protein is delocalized and accumulates in inclusion like bodies instead of being transported to the cell membrane [158, 166]. Interestingly, pathogenic PD mutants of LRRK2 display a similar dysfunctional phenotype, suggesting a direct link between LRRK2 and 14-3-3 signalling.

\subsection{WD40 domain at the C-Terminus of LRRK2}

LRRK2 contains a C-terminal WD40 domain. It comprises seven repeats each of which consists of antiparallel, four stranded $\beta$ - sheets resulting in a circular propeller-like structure. WD40 repeats have a high positive net charge and several hydrophilic surfaces, and are therefore often involved in membrane binding and interaction with negatively charged proteins [157]. Two non-conserved mutations which are suggested to be involved in the onset of PD are found in the WD40 domain of LRRK2: G2385R and T2356I [157]. A yeast-two hybrid screen showed a direct interaction of WD40 repeats with the Roc domain [168]. In addition, LRRK2 lacking the WD40 domain has abolished abilities to form dimers, displays impaired activity and localization [169]. Together these results suggest an important role for the WD40 domain in the intramolecular regulation of LRRK2 activity.

\subsection{LRRK2/Roco activation model}

We have translated all biochemical, genetic and structural data into a model for the regulatory mechanism of LRRK2 (Fig. 4). LRRK2 is monomeric and inactive in the cytosol, but attains pre- 


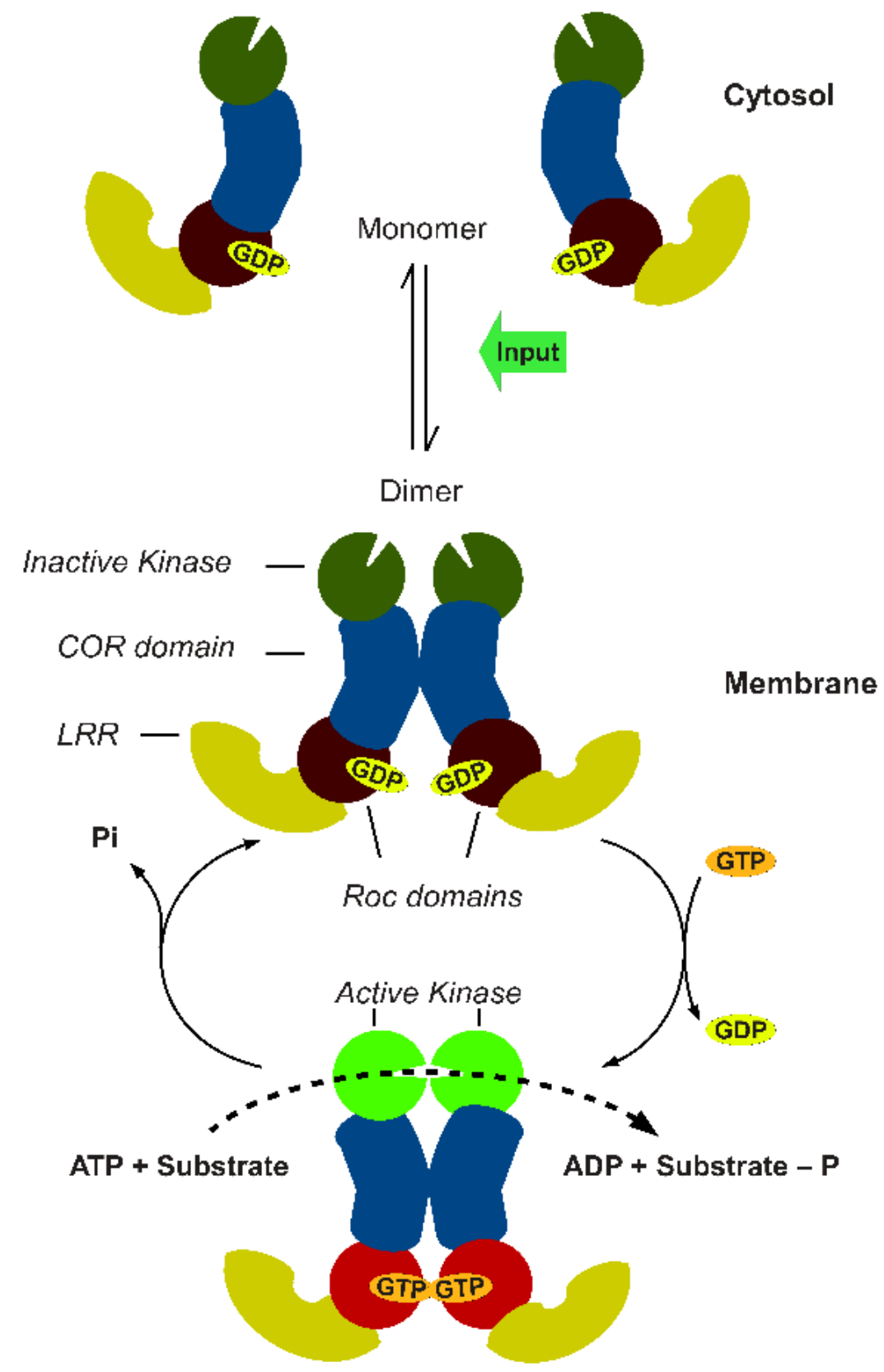

Roc domains come into close proximity

Figure 4. Proposed model for the function and activation mechanism of LRRK2. 
dominantly dimeric and in the active state at the membrane [150]. These results suggest that LRRK2 cycles between a low activity monomeric state and high activity dimeric state. The previously solved structure of the Roco protein from Chlorobium tepidum revealed that COR is the dimerization device and that Roco proteins belong to the GAD class of molecular switches. In the GDP-bound inactive state the G-domains are flexible, but in the active form the Gdomains come in close proximity to each other. This conformational change is transmitted to the kinase domains to allow the activation loops of the two kinase protomers to be autophosphorylated and activated. The GTPase reaction is also dependent on dimerization, because efficient catalytic machinery is formed by complementation of the active site of one protomer with that of the other protomer. In this way the GTPase reaction functions as a timing device for the activation of the kinase and the biological function of the protein. Consistently, PDrelated mutations have reduced GTPase activity and enhanced kinase activity (MS in preparation, [16]). The N- and C- terminal segments are not important for kinase activity in vitro, but appear to be essential in vivo $[114,160,161]$ and most likely determine the input and/or output specificity of the proteins. One of these upstream regulators might be 14-3-3, which binds in a phosphorylation dependent way to the N-terminal segment of LRRK2, thereby regulating its subcellular localization and secretion in exosomes [158, 170, 171].

\section{Therapeutic targeting LRRK2}

The multiple allosteric and enzymatic functions within one protein make LRRK2 an excellent therapeutic target (Fig. 5). Below we highlight the recent progress in identifying LRRK2 kinase inhibitors and discuss alternative ways of targeting LRRK2-mediated PD-disease.

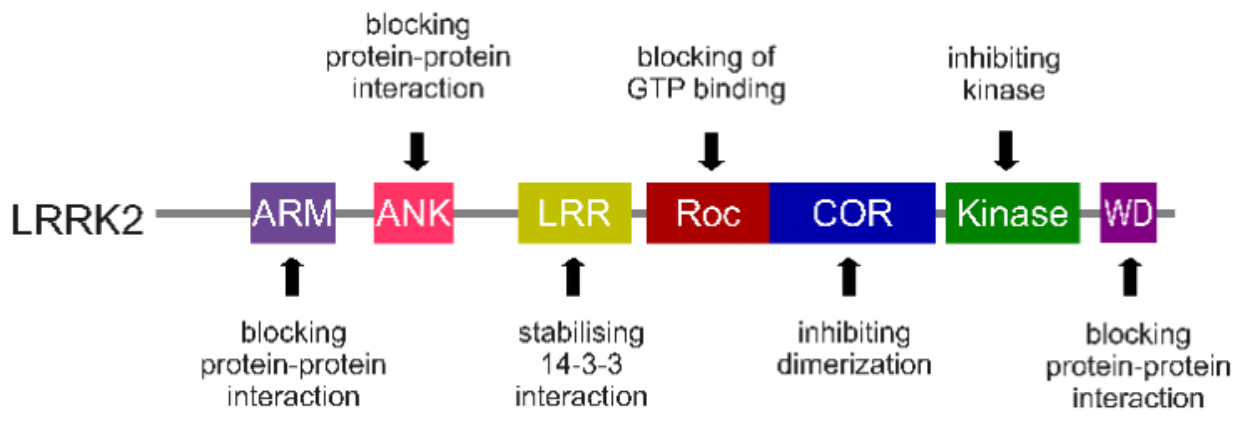

Figure 5. Strategies of LRRK2 inhibition.

\subsection{LRRK2 kinase as a therapeutic target}

Kinases are one of the most potent classes of drug targets and have been effectively used in the treatment of cancer, immunological, neurological and infectious diseases [172]. The 
majority of inhibitors directly target the ATP binding site. They are divided into three groups; most of the inhibitors reported are type I inhibitors, which target the active conformation and directly compete with ATP for the binding pocket. Type II inhibitors also bind in the ATP binding pocket resulting in a change from the active DFG-in into an inactive DFG-out conformation. Type III inhibitors directly target the DFG - out conformation. One of the approved kinase inhibitors for renal cell carcinoma treatment is Sunitinib (Sutent( $\left({ }^{\circ}\right)$, Pfizer Inc.). It is a tyrosine kinase inhibitor which has several targets and inhibits tumor cell proliferation, and angiogenesis [173]. LRRK2 kinase activity is critically linked to clinical effects, and the most prevalent PD mutation, LRRK2 G2019S in the kinase domain, enhances kinase activity by 2-4 folds [108, 141]. Therefore LRRK2 kinase inhibitors are an intensively pursued class of drug targets. Several non selective inhibitors were found to inhibit LRRK2 with their IC50 values in nanomolar range, including staurosporin, K252A and Su-11248 (Sunitinib) [141, 174]. Several ROCK inhibitors have also been found to inhibit LRRK2 with similar efficiencies (low micromolar range), such as isoquinolinesulfonamides hydroxyfasudil and H1152, and the structurally unrelated Y-27632. Noteworthy, not all ROCK inhibitors inhibit LRRK2; isoquinolinesulfonamides do not inhibit LRRK2 as effective as ROCK and the aminofurazan ROCK inhibitor GSK269962A cannot inhibit LRRK2 [175]. Despite a high degree of conservation in the ATP binding site of kinases, it is possible to develop highly selective kinase inhibitors [172]. LRRK2-IN-1 is the first one discovered by compound-centric high throughput library screening [165]. It inhibits both wild-type (IC50 = $13 \mathrm{nM})$ and G2019S mutant (IC50 =6 nM) of LRRK2, and shows high selectivity. Among a panel of 442 kinases, only 12 kinases were inhibited, with up to $10 \mu \mathrm{M}$ of LRRK2-IN-1. LRRK2-IN-1 also inhibits LRRK2 activity in human cells, however dephosphorylation of LRRK2 can only be observed in the kidney and not in the brain of the mice received intraperitoneal injection of the inhibitor, suggesting that this potent and selective LRRK2 inhibitor is incapable of crossing the blood brain barrier [165].

The recently identified LRRK2 inhibitors, HG-10-102-01 [176] and GNE-7915 [177] are selective and brain penetrant [178]. However, long-term inhibition of LRRK2 with these inhibitors leads, similar to disrupting LRRK2 in mice, to kidney abnormality [179-181]. Developing kinase inhibitors specific to PD mutants of LRRK2, not affecting wild-type, might therefore be the most promising approach. The previous solved structure of the Roco4 kinase PD mutant and Roco4 kinase in complex with the LRRK2 inhibitor H1152 might be instrumental in this process [115]. Although current available LRRK2 kinase inhibitor can not be used for PD treatment yet [178], they provide an excellent tool to study PD in vitro and in vivo and form a good starting point to develop better PD drugs.

\subsection{Alternative therapeutic approaches}

Although most attention has concentrated on targeting LRRK2 kinase activity so far, only for the G2019S consistently an increased kinase activity has been reported. All other pathogenic mutations show inconsistent-, modest- or no effect on kinase activity. This suggests that different PD mutations in LRRK2 have a different defect in the activation mechanism and might require different ways of inhibition for the purpose of drug development (Fig. 5). The LRRK2 mutations in the Roc (R1441C/G/H), and COR (Y1699C) domain have a decreased 
GTPase activity [153, 154], suggesting GTPase activity forms a good therapeutic target. Since Ras is the most common oncogene in human cancer, many studies have focussed on identifying Ras inhibitors. Targeting the G-domain could be done by using small compounds that bind to the nucleotide binding site and resemble the GDP bound off state or increase the GTPase reaction. Due to the high nucleotide affinity and the high cytosolic concentration, it has been very challenging to identify a therapeutic target of Ras. However, since LRRK2 has a much lower nucleotide affinity and the GTPase activity is regulated by dimerization, the LRRK2 Gdomain may provide a better therapeutic target.

The N- and C-terminal segments of LRRK2 contain several protein-protein interaction domains which are involved in regulating kinase activity, oligomerization, and/or localization (Fig 5). As described above, LRRK2 cycles between a low active monomeric cytosolic state and high active dimeric membrane bound state. The regulation of LRRK2 membrane association is not well understood, but probably includes dimerization, post-translational modification and protein-protein interactions [158, 170, 182]. 14-3-3 proteins bind in a phosphorylation dependent manner to the N-terminus of LRRK2, which is important for LRRK2 localization and activity [25]. All purified or co-immunoprecipitated LRRK2 fragments are dimeric [148], and LRRK2 kinase activity seems to be dependent on dimerization [150,170]. Active LRRK2 is a constitutive dimer by high affinity interaction of the COR domains, suggesting that in the cytosol the dimerization is most likely covered by regulatory proteins. Importantly, since LRRK2 activation is dependent on membrane localization and dimerization, inhibiting either of these properties may be a good therapeutic approach.

\section{Conclusion}

The multiple disease-linked mutations and enzyme functions within one protein make LRRK2 an excellent therapeutic target. Since several PD mutants result in an increase in LRRK2 kinase activity, the focus so far has been to develop kinase domain inhibitors as potential PD therapeutics. However, alternative approaches that target other domains of LRRK2, localization, dimerization, or allosteric modulation of the kinase domain may have significantly improved therapeutic benefits. To explore these potential therapeutic approaches, it will be essential to completely understand the molecular activation mechanism, identify upstream and downstream regulators, and characterize the cellular function of LRRK2. Work with model organism and biochemical and structural characterization of related Roco proteins from lower organisms might be important in this enterprise.

\section{Acknowledgements}

This work is supported by the Michael J. Fox foundation for Parkinson's research and a NWOVIDI grant to AK. We want to thank Bernd Gilsbach for his input in this chapter. 


\section{Author details}

F.Y. Ho ${ }^{1}$, K.E. Rosenbusch ${ }^{2}$ and A. Kortholt ${ }^{2 *}$

*Address all correspondence to: a.kortholt@rug.nl

1 Department of Biochemistry, University of Groningen, Groningen, The Netherlands

2 Department of Cell Biochemistry, University of Groningen, Groningen, The Netherlands

\section{References}

[1] Lees A.J., Hardy J., and Revesz T. (2009). Parkinson's disease. Lancet 373: 2055-2066.

[2] Bekris L.M., Mata I.F., and Zabetian C.P. (2010). The genetics of Parkinson disease. J. Geriatr. Psychiatry Neurol. 23: 228-242.

[3] Satake W., Nakabayashi Y., Mizuta I., Hirota Y., Ito C., Kubo M., Kawaguchi T., Tsunoda T., Watanabe M., Takeda A. et al. (2009). Genome-wide association study identifies common variants at four loci as genetic risk factors for Parkinson's disease. Nat. Genet. 41: 1303-1307.

[4] Singleton A.B., Farrer M.J., and Bonifati V. (2013). The genetics of Parkinson's disease: progress and therapeutic implications. Mov Disord. 28: 14-23.

[5] Sundal C., Fujioka S., Uitti R.J., and Wszolek Z.K. (2012). Autosomal dominant Parkinson's disease. Parkinsonism. Relat Disord. 18 Suppl 1: S7-10.

[6] Paisan-Ruiz C., Jain S., Evans E.W., Gilks W.P., Simon J., van der B.M., Lopez d.M., Aparicio S., Gil A.M., Khan N. et al. (2004). Cloning of the gene containing mutations that cause PARK8-linked Parkinson's disease. Neuron 44: 595-600.

[7] Zimprich A., Biskup S., Leitner P., Lichtner P., Farrer M., Lincoln S., Kachergus J., Hulihan M., Uitti R.J., Calne D.B. et al. (2004). Mutations in LRRK2 cause autosomaldominant parkinsonism with pleomorphic pathology. Neuron 44: 601-607.

[8] Gilks W.P., bou-Sleiman P.M., Gandhi S., Jain S., Singleton A., Lees A.J., Shaw K., Bhatia K.P., Bonifati V., Quinn N.P. et al. (2005). A common LRRK2 mutation in idiopathic Parkinson's disease. Lancet 365: 415-416.

[9] Farrer M.J. (2006). Genetics of Parkinson disease: paradigm shifts and future prospects. Nat. Rev. Genet. 7: 306-318.

[10] Healy D.G., Falchi M., O'Sullivan S.S., Bonifati V., Durr A., Bressman S., Brice A., Aasly J., Zabetian C.P., Goldwurm S. et al. (2008). Phenotype, genotype, and world- 
wide genetic penetrance of LRRK2-associated Parkinson's disease: a case-control study. Lancet Neurol. 7: 583-590.

[11] Marras C., Schule B., Munhoz R.P., Rogaeva E., Langston J.W., Kasten M., Meaney C., Klein C., Wadia P.M., Lim S.Y. et al. (2011). Phenotype in parkinsonian and nonparkinsonian LRRK2 G2019S mutation carriers. Neurology 77: 325-333.

[12] Gaig C., Marti M.J., Ezquerra M., Rey M.J., Cardozo A., and Tolosa E. (2007). G2019S LRRK2 mutation causing Parkinson's disease without Lewy bodies. J. Neurol. Neurosurg. Psychiatry 78: 626-628.

[13] Goldwurm S., Zini M., Di F.A., De G.D., Siri C., Simons E.J., van D.M., Tesei S., Antonini A., Canesi M. et al. (2006). LRRK2 G2019S mutation and Parkinson's disease: a clinical, neuropsychological and neuropsychiatric study in a large Italian sample. Parkinsonism. Relat Disord. 12: 410-419.

[14] Zhu X., Siedlak S.L., Smith M.A., Perry G., and Chen S.G. (2006). LRRK2 protein is a component of Lewy bodies. Ann. Neurol. 60: 617-618.

[15] Bosgraaf L. and van Haastert P.J. (2003). Roc, a Ras/GTPase domain in complex proteins. Biochim. Biophys. Acta 1643: 5-10.

[16] Cookson M.R. and Bandmann O. (2010). Parkinson's disease: insights from pathways. Hum. Mol. Genet. 19: R21-R27.

[17] Cookson M.R. (2010). The role of leucine-rich repeat kinase 2 (LRRK2) in Parkinson's disease. Nat. Rev. Neurosci. 11: 791-797.

[18] MacLeod D., Dowman J., Hammond R., Leete T., Inoue K., and Abeliovich A. (2006). The familial Parkinsonism gene LRRK2 regulates neurite process morphology. Neuron 52: 587-593.

[19] Sepulveda B., Mesias R., Li X., Yue Z., and Benson D.L. (2013). Short- and long-term effects of LRRK2 on axon and dendrite growth. PLoS. One. 8: e61986.

[20] Dachsel J.C., Behrouz B., Yue M., Beevers J.E., Melrose H.L., and Farrer M.J. (2010). A comparative study of Lrrk2 function in primary neuronal cultures. Parkinsonism. Relat Disord. 16: 650-655.

[21] Winner B., Melrose H.L., Zhao C., Hinkle K.M., Yue M., Kent C., Braithwaite A.T., Ogholikhan S., Aigner R., Winkler J. et al. (2011). Adult neurogenesis and neurite outgrowth are impaired in LRRK2 G2019S mice. Neurobiol. Dis. 41: 706-716.

[22] Sheng Z., Zhang S., Bustos D., Kleinheinz T., Le Pichon C.E., Dominguez S.L., Solanoy H.O., Drummond J., Zhang X., Ding X. et al. (2012). Ser1292 autophosphorylation is an indicator of LRRK2 kinase activity and contributes to the cellular effects of PD mutations. Sci. Transl. Med. 4: 164ra161. 
[23] Zechel S., Meinhardt A., Unsicker K., and von Bohlen Und H.O. (2010). Expression of leucine-rich-repeat-kinase 2 (LRRK2) during embryonic development. Int. J. Dev. Neurosci. 28: 391-399.

[24] varez-Buylla A. and Lim D.A. (2004). For the long run: maintaining germinal niches in the adult brain. Neuron 41: 683-686.

[25] Bahnassawy L., Nicklas S., Palm T., Menzl I., Birzele F., Gillardon F., and Schwamborn J.C. (2013). The Parkinson's Disease-Associated LRRK2 Mutation R1441G Inhibits Neuronal Differentiation of Neural Stem Cells. Stem Cells Dev. 22: 2487-2496.

[26] Liu G.H., Qu J., Suzuki K., Nivet E., Li M., Montserrat N., Yi F., Xu X., Ruiz S., Zhang W. et al. (2012). Progressive degeneration of human neural stem cells caused by pathogenic LRRK2. Nature 491: 603-607.

[27] Winner B., Melrose H.L., Zhao C., Hinkle K.M., Yue M., Kent C., Braithwaite A.T., Ogholikhan S., Aigner R., Winkler J. et al. (2011). Adult neurogenesis and neurite outgrowth are impaired in LRRK2 G2019S mice. Neurobiol. Dis. 41: 706-716.

[28] Schulz C., Paus M., Frey K., Schmid R., Kohl Z., Mennerich D., Winkler J., and Gillardon F. (2011). Leucine-rich repeat kinase 2 modulates retinoic acid-induced neuronal differentiation of murine embryonic stem cells. PLoS. One. 6: e20820.

[29] Paus M., Kohl Z., Ben Abdallah N.M., Galter D., Gillardon F., and Winkler J. (2013). Enhanced dendritogenesis and axogenesis in hippocampal neuroblasts of LRRK2 knockout mice. Brain Res. 1497: 85-100.

[30] Caesar M., Zach S., Carlson C.B., Brockmann K., Gasser T., and Gillardon F. (2013). Leucine-rich repeat kinase 2 functionally interacts with microtubules and kinase-dependently modulates cell migration. Neurobiol. Dis. 54: 280-288.

[31] Chan D., Citro A., Cordy J.M., Shen G.C., and Wolozin B. (2011). Rac1 protein rescues neurite retraction caused by G2019S leucine-rich repeat kinase 2 (LRRK2). J. Biol. Chem. 286: 16140-16149.

[32] Gandhi P.N., Wang X., Zhu X., Chen S.G., and Wilson-Delfosse A.L. (2008). The Roc domain of leucine-rich repeat kinase 2 is sufficient for interaction with microtubules. J. Neurosci. Res. 86: 1711-1720.

[33] Sancho R.M., Law B.M., and Harvey K. (2009). Mutations in the LRRK2 Roc-COR tandem domain link Parkinson's disease to Wnt signalling pathways. Hum. Mol. Genet. 18: 3955-3968.

[34] Stafa K., Trancikova A., Webber P.J., Glauser L., West A.B., and Moore D.J. (2012). GTPase activity and neuronal toxicity of Parkinson's disease-associated LRRK2 is regulated by ArfGAP1. PLoS. Genet. 8: e1002526.

[35] Ille F. and Sommer L. (2005). Wnt signaling: multiple functions in neural development. Cell Mol. Life Sci. 62: 1100-1108. 
[36] Inestrosa N.C. and Arenas E. (2010). Emerging roles of Wnts in the adult nervous system. Nat. Rev. Neurosci. 11: 77-86.

[37] Ding S., Wu T.Y., Brinker A., Peters E.C., Hur W., Gray N.S., and Schultz P.G. (2003). Synthetic small molecules that control stem cell fate. Proc. Natl. Acad. Sci. U. S. A 100: $7632-7637$.

[38] Hirabayashi Y., Itoh Y., Tabata H., Nakajima K., Akiyama T., Masuyama N., and Gotoh Y. (2004). The Wnt/beta-catenin pathway directs neuronal differentiation of cortical neural precursor cells. Development 131: 2791-2801.

[39] Berwick D.C. and Harvey K. (2013). LRRK2: an eminence grise of Wnt-mediated neurogenesis? Front Cell Neurosci. 7: 82.

[40] Kroemer G. and Levine B. (2008). Autophagic cell death: the story of a misnomer. Nat. Rev. Mol. Cell Biol. 9: 1004-1010.

[41] Janda E., Isidoro C., Carresi C., and Mollace V. (2012). Defective autophagy in Parkinson's disease: role of oxidative stress. Mol. Neurobiol. 46: 639-661.

[42] Rami A. (2009). Review: autophagy in neurodegeneration: firefighter and/or incendiarist? Neuropathol. Appl. Neurobiol. 35: 449-461.

[43] Sharon R., Bar-Joseph I., Frosch M.P., Walsh D.M., Hamilton J.A., and Selkoe D.J. (2003). The formation of highly soluble oligomers of alpha-synuclein is regulated by fatty acids and enhanced in Parkinson's disease. Neuron 37: 583-595.

[44] Walsh D.M., Klyubin I., Fadeeva J.V., Cullen W.K., Anwyl R., Wolfe M.S., Rowan M.J., and Selkoe D.J. (2002). Naturally secreted oligomers of amyloid beta protein potently inhibit hippocampal long-term potentiation in vivo. Nature 416: 535-539.

[45] Maeda S., Sahara N., Saito Y., Murayama S., Ikai A., and Takashima A. (2006). Increased levels of granular tau oligomers: an early sign of brain aging and Alzheimer's disease. Neurosci. Res. 54: 197-201.

[46] Webb A., Clark P., Skepper J., Compston A., and Wood A. (1995). Guidance of oligodendrocytes and their progenitors by substratum topography. J. Cell Sci. 108 ( Pt 8): 2747-2760.

[47] Wang Y., Kruger U., Mandelkow E., and Mandelkow E.M. (2010). Generation of tau aggregates and clearance by autophagy in an inducible cell model of tauopathy. Neurodegener. Dis. 7: 103-107.

[48] Sarkar S. and Rubinsztein D.C. (2008). Huntington's disease: degradation of mutant huntingtin by autophagy. FEBS J. 275: 4263-4270.

[49] Hara T., Nakamura K., Matsui M., Yamamoto A., Nakahara Y., Suzuki-Migishima R., Yokoyama M., Mishima K., Saito I., Okano H. et al. (2006). Suppression of basal autophagy in neural cells causes neurodegenerative disease in mice. Nature 441: 885-889. 
[50] Komatsu M., Wang Q.J., Holstein G.R., Friedrich V.L., Jr., Iwata J., Kominami E., Chait B.T., Tanaka K., and Yue Z. (2007). Essential role for autophagy protein Atg7 in the maintenance of axonal homeostasis and the prevention of axonal degeneration. Proc. Natl. Acad. Sci. U. S. A 104: 14489-14494.

[51] Komatsu M., Waguri S., Chiba T., Murata S., Iwata J., Tanida I., Ueno T., Koike M., Uchiyama Y., Kominami E. et al. (2006). Loss of autophagy in the central nervous system causes neurodegeneration in mice. Nature 441: 880-884.

[52] Nishiyama J., Miura E., Mizushima N., Watanabe M., and Yuzaki M. (2007). Aberrant membranes and double-membrane structures accumulate in the axons of Atg5-null Purkinje cells before neuronal death. Autophagy. 3: 591-596.

[53] Ahmed I., Liang Y., Schools S., Dawson V.L., Dawson T.M., and Savitt J.M. (2012). Development and characterization of a new Parkinson's disease model resulting from impaired autophagy. J. Neurosci. 32: 16503-16509.

[54] Plowey E.D., Cherra S.J., III, Liu Y.J., and Chu C.T. (2008). Role of autophagy in G2019S-LRRK2-associated neurite shortening in differentiated SH-SY5Y cells. J. Neurochem. 105: 1048-1056.

[55] egre-Abarrategui J., Christian H., Lufino M.M., Mutihac R., Venda L.L., Ansorge O., and Wade-Martins R. (2009). LRRK2 regulates autophagic activity and localizes to specific membrane microdomains in a novel human genomic reporter cellular model. Hum. Mol. Genet. 18: 4022-4034.

[56] Bravo-San Pedro J.M., Niso-Santano M., Gomez-Sanchez R., Pizarro-Estrella E., iastui-Pujana A., Gorostidi A., Climent V., Lopez de M.R., Sanchez-Pernaute R., Lopez de M.A. et al. (2013). The LRRK2 G2019S mutant exacerbates basal autophagy through activation of the MEK/ERK pathway. Cell Mol. Life Sci. 70: 121-136.

[57] Gomez-Suaga P., Luzon-Toro B., Churamani D., Zhang L., Bloor-Young D., Patel S., Woodman P.G., Churchill G.C., and Hilfiker S. (2012). Leucine-rich repeat kinase 2 regulates autophagy through a calcium-dependent pathway involving NAADP. Hum. Mol. Genet. 21: 511-525.

[58] Ramonet D., Daher J.P., Lin B.M., Stafa K., Kim J., Banerjee R., Westerlund M., Pletnikova O., Glauser L., Yang L. et al. (2011). Dopaminergic neuronal loss, reduced neurite complexity and autophagic abnormalities in transgenic mice expressing G2019S mutant LRRK2. PLoS. One. 6: e18568.

[59] Manzoni C., Mamais A., Dihanich S., Abeti R., Soutar M.P., Plun-Favreau H., Giunti P., Tooze S.A., Bandopadhyay R., and Lewis P.A. (2013). Inhibition of LRRK2 kinase activity stimulates macroautophagy. Biochim. Biophys. Acta 1833: 2900-2910.

[60] Orenstein S.J., Kuo S.H., Tasset I., Arias E., Koga H., Fernandez-Carasa I., Cortes E., Honig L.S., Dauer W., Consiglio A. et al. (2013). Interplay of LRRK2 with chaperonemediated autophagy. Nat. Neurosci. 16: 394-406. 
[61] Biskup S., Moore D.J., Celsi F., Higashi S., West A.B., Andrabi S.A., Kurkinen K., Yu S.W., Savitt J.M., Waldvogel H.J. et al. (2006). Localization of LRRK2 to membranous and vesicular structures in mammalian brain. Ann. Neurol. 60: 557-569.

[62] Papkovskaia T.D., Chau K.Y., Inesta-Vaquera F., Papkovsky D.B., Healy D.G., Nishio K., Staddon J., Duchen M.R., Hardy J., Schapira A.H. et al. (2012). G2019S leucinerich repeat kinase 2 causes uncoupling protein-mediated mitochondrial depolarization. Hum. Mol. Genet. 21: 4201-4213.

[63] Mortiboys H., Johansen K.K., Aasly J.O., and Bandmann O. (2010). Mitochondrial impairment in patients with Parkinson disease with the G2019S mutation in LRRK2. Neurology 75: 2017-2020.

[64] Lin M.T. and Beal M.F. (2006). Mitochondrial dysfunction and oxidative stress in neurodegenerative diseases. Nature 443: 787-795.

[65] Valente E.M., bou-Sleiman P.M., Caputo V., Muqit M.M., Harvey K., Gispert S., Ali Z., Del T.D., Bentivoglio A.R., Healy D.G. et al. (2004). Hereditary early-onset Parkinson's disease caused by mutations in PINK1. Science 304: 1158-1160.

[66] Wang X., Yan M.H., Fujioka H., Liu J., Wilson-Delfosse A., Chen S.G., Perry G., Casadesus G., and Zhu X. (2012). LRRK2 regulates mitochondrial dynamics and function through direct interaction with DLP1. Hum. Mol. Genet. 21: 1931-1944.

[67] Perry G., Zhu X., Babar A.K., Siedlak S.L., Yang Q., Ito G., Iwatsubo T., Smith M.A., and Chen S.G. (2008). Leucine-rich repeat kinase 2 colocalizes with alpha-synuclein in Parkinson's disease, but not tau-containing deposits in tauopathies. Neurodegener. Dis. 5: 222-224.

[68] Guerreiro P.S., Huang Y., Gysbers A., Cheng D., Gai W.P., Outeiro T.F., and Halliday G.M. (2013). LRRK2 interactions with alpha-synuclein in Parkinson's disease brains and in cell models. J. Mol. Med. (Berl) 91: 513-522.

[69] Maroteaux L., Campanelli J.T., and Scheller R.H. (1988). Synuclein: a neuron-specific protein localized to the nucleus and presynaptic nerve terminal. J. Neurosci. 8: 2804-2815.

[70] Kahle P.J., Neumann M., Ozmen L., Muller V., Jacobsen H., Schindzielorz A., Okochi M., Leimer U., van Der P.H., Probst A. et al. (2000). Subcellular localization of wildtype and Parkinson's disease-associated mutant alpha -synuclein in human and transgenic mouse brain. J. Neurosci. 20: 6365-6373.

[71] Fortin D.L., Troyer M.D., Nakamura K., Kubo S., Anthony M.D., and Edwards R.H. (2004). Lipid rafts mediate the synaptic localization of alpha-synuclein. J. Neurosci. 24: 6715-6723.

[72] Burre J., Sharma M., Tsetsenis T., Buchman V., Etherton M.R., and Sudhof T.C. (2010). Alpha-synuclein promotes SNARE-complex assembly in vivo and in vitro. Science 329: 1663-1667. 
[73] Diao J., Burre J., Vivona S., Cipriano D.J., Sharma M., Kyoung M., Sudhof T.C., and Brunger A.T. (2013). Native alpha-synuclein induces clustering of synaptic-vesicle mimics via binding to phospholipids and synaptobrevin-2/VAMP2. Elife. 2: e00592.

[74] Larsen K.E., Schmitz Y., Troyer M.D., Mosharov E., Dietrich P., Quazi A.Z., Savalle M., Nemani V., Chaudhry F.A., Edwards R.H. et al. (2006). Alpha-synuclein overexpression in PC12 and chromaffin cells impairs catecholamine release by interfering with a late step in exocytosis. J. Neurosci. 26: 11915-11922.

[75] Thayanidhi N., Helm J.R., Nycz D.C., Bentley M., Liang Y., and Hay J.C. (2010). Alpha-synuclein delays endoplasmic reticulum (ER)-to-Golgi transport in mammalian cells by antagonizing ER/Golgi SNAREs. Mol. Biol. Cell 21: 1850-1863.

[76] Sancenon V., Lee S.A., Patrick C., Griffith J., Paulino A., Outeiro T.F., Reggiori F., Masliah E., and Muchowski P.J. (2012). Suppression of alpha-synuclein toxicity and vesicle trafficking defects by phosphorylation at S129 in yeast depends on genetic context. Hum. Mol. Genet. 21: 2432-2449.

[77] Qing H., Wong W., McGeer E.G., and McGeer P.L. (2009). Lrrk2 phosphorylates alpha synuclein at serine 129: Parkinson disease implications. Biochem. Biophys. Res. Commun. 387: 149-152.

[78] Tong Y., Yamaguchi H., Giaime E., Boyle S., Kopan R., Kelleher R.J., III, and Shen J. (2010). Loss of leucine-rich repeat kinase 2 causes impairment of protein degradation pathways, accumulation of alpha-synuclein, and apoptotic cell death in aged mice. Proc. Natl. Acad. Sci. U. S. A 107: 9879-9884.

[79] Westerlund M., Ran C., Borgkvist A., Sterky F.H., Lindqvist E., Lundstromer K., Pernold K., Brene S., Kallunki P., Fisone G. et al. (2008). Lrrk2 and alpha-synuclein are co-regulated in rodent striatum. Mol. Cell Neurosci. 39: 586-591.

[80] Dalfo E., Barrachina M., Rosa J.L., Ambrosio S., and Ferrer I. (2004). Abnormal alphasynuclein interactions with rab3a and rabphilin in diffuse Lewy body disease. Neurobiol. Dis. 16: 92-97.

[81] Shin N., Jeong H., Kwon J., Heo H.Y., Kwon J.J., Yun H.J., Kim C.H., Han B.S., Tong Y., Shen J. et al. (2008). LRRK2 regulates synaptic vesicle endocytosis. Exp. Cell Res. 314: 2055-2065.

[82] Klein C. and Lohmann-Hedrich K. (2007). Impact of recent genetic findings in Parkinson's disease. Curr. Opin. Neurol. 20: 453-464.

[83] Clark I.E., Dodson M.W., Jiang C., Cao J.H., Huh J.R., Seol J.H., Yoo S.J., Hay B.A., and Guo M. (2006). Drosophila pink1 is required for mitochondrial function and interacts genetically with parkin. Nature 441: 1162-1166.

[84] Gautier C.A., Kitada T., and Shen J. (2008). Loss of PINK1 causes mitochondrial functional defects and increased sensitivity to oxidative stress. Proc. Natl. Acad. Sci. U. S. A 105: 11364-11369. 
[85] Matsuda S., Kitagishi Y., and Kobayashi M. (2013). Function and characteristics of PINK1 in mitochondria. Oxid. Med. Cell Longev. 2013: 601587.

[86] Ng C.H., Guan M.S., Koh C., Ouyang X., Yu F., Tan E.K., O'Neill S.P., Zhang X., Chung J., and Lim K.L. (2012). AMP kinase activation mitigates dopaminergic dysfunction and mitochondrial abnormalities in Drosophila models of Parkinson's disease. J. Neurosci. 32: 14311-14317.

[87] Venderova K., Kabbach G., bdel-Messih E., Zhang Y., Parks R.J., Imai Y., Gehrke S., Ngsee J., LaVoie M.J., Slack R.S. et al. (2009). Leucine-Rich Repeat Kinase 2 interacts with Parkin, DJ-1 and PINK-1 in a Drosophila melanogaster model of Parkinson's disease. Hum. Mol. Genet. 18: 4390-4404.

[88] Ariga H., Takahashi-Niki K., Kato I., Maita H., Niki T., and Iguchi-Ariga S.M. (2013). Neuroprotective function of DJ-1 in Parkinson's disease. Oxid. Med. Cell Longev. 2013: 683920 .

[89] Bjorkblom B., Adilbayeva A., Maple-Grodem J., Piston D., Okvist M., Xu X.M., Brede C., Larsen J.P., and Moller S.G. (2013). Parkinson Disease Protein DJ-1 Binds Metals and Protects against Metal-induced Cytotoxicity. J. Biol. Chem. 288: 22809-22820.

[90] Kinumi T., Kimata J., Taira T., Ariga H., and Niki E. (2004). Cysteine-106 of DJ-1 is the most sensitive cysteine residue to hydrogen peroxide-mediated oxidation in vivo in human umbilical vein endothelial cells. Biochem. Biophys. Res. Commun. 317: 722-728.

[91] Betarbet R., Canet-Aviles R.M., Sherer T.B., Mastroberardino P.G., McLendon C., Kim J.H., Lund S., Na H.M., Taylor G., Bence N.F. et al. (2006). Intersecting pathways to neurodegeneration in Parkinson's disease: effects of the pesticide rotenone on DJ-1, alpha-synuclein, and the ubiquitin-proteasome system. Neurobiol. Dis. 22: 404-420.

[92] Irrcher I., Aleyasin H., Seifert E.L., Hewitt S.J., Chhabra S., Phillips M., Lutz A.K., Rousseaux M.W., Bevilacqua L., Jahani-Asl A. et al. (2010). Loss of the Parkinson's disease-linked gene DJ-1 perturbs mitochondrial dynamics. Hum. Mol. Genet. 19: 3734-3746.

[93] Thomas K.J., McCoy M.K., Blackinton J., Beilina A., van der B.M., Sandebring A., Miller D., Maric D., Cedazo-Minguez A., and Cookson M.R. (2011). DJ-1 acts in parallel to the PINK1/parkin pathway to control mitochondrial function and autophagy. Hum. Mol. Genet. 20: 40-50.

[94] Saunders-Pullman R., Barrett M.J., Stanley K.M., Luciano M.S., Shanker V., Severt L., Hunt A., Raymond D., Ozelius L.J., and Bressman S.B. (2010). LRRK2 G2019S mutations are associated with an increased cancer risk in Parkinson disease. Mov Disord. 25: 2536-2541.

[95] Inzelberg R., Cohen O.S., haron-Peretz J., Schlesinger I., Gershoni-Baruch R., Djaldetti R., Nitsan Z., Ephraty L., Tunkel O., Kozlova E. et al. (2012). The LRRK2 G2019S 
mutation is associated with Parkinson disease and concomitant non-skin cancers. Neurology 78: 781-786.

[96] Pons B., Armengol G., Livingstone M., Lopez L., Coch L., Sonenberg N., and Cajal S. (2012). Association between LRRK2 and 4E-BP1 protein levels in normal and malignant cells. Oncol. Rep. 27: 225-231.

[97] Martin D., Nguyen Q., Molinolo A., and Gutkind J.S. (2013). Accumulation of dephosphorylated 4EBP after mTOR inhibition with rapamycin is sufficient to disrupt paracrine transformation by the KSHV vGPCR oncogene. Oncogene.

[98] Guertin D.A. and Sabatini D.M. (2005). An expanding role for mTOR in cancer. Trends Mol. Med. 11: 353-361.

[99] Barrett J.C., Hansoul S., Nicolae D.L., Cho J.H., Duerr R.H., Rioux J.D., Brant S.R., Silverberg M.S., Taylor K.D., Barmada M.M. et al. (2008). Genome-wide association defines more than 30 distinct susceptibility loci for Crohn's disease. Nat. Genet. 40: 955-962.

[100] Zhang F.R., Huang W., Chen S.M., Sun L.D., Liu H., Li Y., Cui Y., Yan X.X., Yang H.T., Yang R.D. et al. (2009). Genomewide association study of leprosy. N. Engl. J. Med. 361: 2609-2618.

[101] Marks D.J., Harbord M.W., MacAllister R., Rahman F.Z., Young J., Al-Lazikani B., Lees W., Novelli M., Bloom S., and Segal A.W. (2006). Defective acute inflammation in Crohn's disease: a clinical investigation. Lancet 367: 668-678.

[102] Actis G.C. and Rosina F. (2013). Inflammatory bowel disease: An archetype disorder of outer environment sensor systems. World J. Gastrointest. Pharmacol. Ther. 4: 41-46.

[103] Hakimi M., Selvanantham T., Swinton E., Padmore R.F., Tong Y., Kabbach G., Venderova K., Girardin S.E., Bulman D.E., Scherzer C.R. et al. (2011). Parkinson's diseaselinked LRRK2 is expressed in circulating and tissue immune cells and upregulated following recognition of microbial structures. J. Neural Transm. 118: 795-808.

[104] Maekawa T., Kubo M., Yokoyama I., Ohta E., and Obata F. (2010). Age-dependent and cell-population-restricted LRRK2 expression in normal mouse spleen. Biochem. Biophys. Res. Commun. 392: 431-435.

[105] Gardet A., Benita Y., Li C., Sands B.E., Ballester I., Stevens C., Korzenik J.R., Rioux J.D., Daly M.J., Xavier R.J. et al. (2010). LRRK2 is involved in the IFN-gamma response and host response to pathogens. J. Immunol. 185: 5577-5585.

[106] Liu Z., Lee J., Krummey S., Lu W., Cai H., and Lenardo M.J. (2011). The kinase LRRK2 is a regulator of the transcription factor NFAT that modulates the severity of inflammatory bowel disease. Nat. Immunol. 12: 1063-1070. 
[107] Greggio E. and Cookson M.R. (2009). Leucine-rich repeat kinase 2 mutations and Parkinson's disease: three questions. ASN. Neuro. 1.

[108] Luzon-Toro B., Rubio d.1.T., Delgado A., Perez-Tur J., and Hilfiker S. (2007). Mechanistic insight into the dominant mode of the Parkinson's disease-associated G2019S LRRK2 mutation. Hum. Mol. Genet. 16: 2031-2039.

[109] West A.B., Moore D.J., Biskup S., Bugayenko A., Smith W.W., Ross C.A., Dawson V.L., and Dawson T.M. (2005). Parkinson's disease-associated mutations in leucinerich repeat kinase 2 augment kinase activity. Proc. Natl. Acad. Sci. U. S A 102: 16842-16847.

[110] Itoh N. and Nagata S. (1993). A novel protein domain required for apoptosis. Mutational analysis of human Fas antigen. J. Biol. Chem. 268: 10932-10937.

[111] Eichinger L., Pachebat J.A., Glockner G., Rajandream M.A., Sucgang R., Berriman M., Song J., Olsen R., Szafranski K., Xu Q. et al. (2005). The genome of the social amoeba Dictyostelium discoideum. Nature 435: 43-57.

[112] Muller-Taubenberger A., Kortholt A., and Eichinger L. (2013). Simple system--substantial share: the use of Dictyostelium in cell biology and molecular medicine. Eur. J. Cell Biol. 92: 45-53.

[113] Marin I. (2006). The Parkinson disease gene LRRK2: evolutionary and structural insights. Mol. Biol. Evol. 23: 2423-2433.

[114] van Egmond W.N. and van Haastert P.J. (2010). Characterization of the Roco protein family in Dictyostelium discoideum. Eukaryot. Cell 9: 751-761.

[115] Gilsbach B.K., Ho F.Y., Vetter I.R., van Haastert P.J., Wittinghofer A., and Kortholt A. (2012). Roco kinase structures give insights into the mechanism of Parkinson diseaserelated leucine-rich-repeat kinase 2 mutations. Proc. Natl. Acad. Sci. U. S. A.

[116] Bonner J.T. (1947). Evidence for the formation of cell aggregates by chemotaxis in the development of the slime mold Dictyostelium discoideum. J. Exp. Zool. 106: 1-26.

[117] Jaleel M., Nichols R.J., Deak M., Campbell D.G., Gillardon F., Knebel A., and Alessi D.R. (2007). LRRK2 phosphorylates moesin at threonine-558: characterization of how Parkinson's disease mutants affect kinase activity. Biochem. J. 405: 307-317.

[118] Taylor S.S. and Kornev A.P. (2011). Protein kinases: evolution of dynamic regulatory proteins. Trends Biochem. Sci. 36: 65-77.

[119] Endicott J.A., Noble M.E., and Johnson L.N. (2012). The structural basis for control of eukaryotic protein kinases. Annu. Rev. Biochem. 81: 587-613.

[120] Greggio E., Jain S., Kingsbury A., Bandopadhyay R., Lewis P., Kaganovich A., van der Brug M.P., Beilina A., Blackinton J., Thomas K.J. et al. (2006). Kinase activity is required for the toxic effects of mutant LRRK2/dardarin. Neurobiol. Dis. 23: 329-341. 
[121] Smith W.W., Pei Z., Jiang H., Dawson V.L., Dawson T.M., and Ross C.A. (2006). Kinase activity of mutant LRRK2 mediates neuronal toxicity. Nat. Neurosci. 9: 1231-1233.

[122] Huse M. and Kuriyan J. (2002). The conformational plasticity of protein kinases. Cell 109: 275-282.

[123] Adams J.A. (2003). Activation loop phosphorylation and catalysis in protein kinases: is there functional evidence for the autoinhibitor model? Biochemistry 42: 601-607.

[124] Kornev A.P., Haste N.M., Taylor S.S., and Eyck L.F. (2006). Surface comparison of active and inactive protein kinases identifies a conserved activation mechanism. Proc. Natl. Acad. Sci. U. S. A 103: 17783-17788.

[125] Li X., Moore D.J., Xiong Y., Dawson T.M., and Dawson V.L. (2010). Reevaluation of phosphorylation sites in the Parkinson disease-associated leucine-rich repeat kinase 2. J. Biol. Chem. 285: 29569-29576.

[126] Kamikawaji S., Ito G., and Iwatsubo T. (2009). Identification of the autophosphorylation sites of LRRK2. Biochemistry 48: 10963-10975.

[127] Webber P.J., Smith A.D., Sen S., Renfrow M.B., Mobley J.A., and West A.B. (2011). Autophosphorylation in the leucine-rich repeat kinase 2 (LRRK2) GTPase domain modifies kinase and GTP-binding activities. J. Mol. Biol. 412: 94-110.

[128] Imai Y., Gehrke S., Wang H.Q., Takahashi R., Hasegawa K., Oota E., and Lu B. (2008). Phosphorylation of 4E-BP by LRRK2 affects the maintenance of dopaminergic neurons in Drosophila. EMBO J. 27: 2432-2443.

[129] Kumar A., Greggio E., Beilina A., Kaganovich A., Chan D., Taymans J.M., Wolozin B., and Cookson M.R. (2010). The Parkinson's disease associated LRRK2 exhibits weaker in vitro phosphorylation of 4E-BP compared to autophosphorylation. PLoS. One. 5: e8730.

[130] Lee S., Liu H.P., Lin W.Y., Guo H., and Lu B. (2010). LRRK2 kinase regulates synaptic morphology through distinct substrates at the presynaptic and postsynaptic compartments of the Drosophila neuromuscular junction. J. Neurosci. 30: 16959-16969.

[131] Trancikova A., Mamais A., Webber P.J., Stafa K., Tsika E., Glauser L., West A.B., Bandopadhyay R., and Moore D.J. (2012). Phosphorylation of 4E-BP1 in the mammalian brain is not altered by LRRK2 expression or pathogenic mutations. PLoS. One. 7: e47784.

[132] Kanao T., Venderova K., Park D.S., Unterman T., Lu B., and Imai Y. (2010). Activation of FoxO by LRRK2 induces expression of proapoptotic proteins and alters survival of postmitotic dopaminergic neuron in Drosophila. Hum. Mol. Genet. 19: 3747-3758. 
[133] Gilley J., Coffer P.J., and Ham J. (2003). FOXO transcription factors directly activate bim gene expression and promote apoptosis in sympathetic neurons. J. Cell Biol. 162: 613-622.

[134] Park S.J., Sohn H.Y., Yoon J., and Park S.I. (2009). Down-regulation of FoxO-dependent c-FLIP expression mediates TRAIL-induced apoptosis in activated hepatic stellate cells. Cell Signal. 21: 1495-1503.

[135] Xu P., Das M., Reilly J., and Davis R.J. (2011). JNK regulates FoxO-dependent autophagy in neurons. Genes Dev. 25: 310-322.

[136] Parisiadou L., Xie C., Cho H.J., Lin X., Gu X.L., Long C.X., Lobbestael E., Baekelandt V., Taymans J.M., Sun L. et al. (2009). Phosphorylation of ezrin/radixin/moesin proteins by LRRK2 promotes the rearrangement of actin cytoskeleton in neuronal morphogenesis. J. Neurosci. 29: 13971-13980.

[137] Parisiadou L. and Cai H. (2010). LRRK2 function on actin and microtubule dynamics in Parkinson disease. Commun. Integr. Biol. 3: 396-400.

[138] Gillardon F. (2009). Leucine-rich repeat kinase 2 phosphorylates brain tubulin-beta isoforms and modulates microtubule stability--a point of convergence in parkinsonian neurodegeneration? J. Neurochem. 110: 1514-1522.

[139] Kawakami F., Yabata T., Ohta E., Maekawa T., Shimada N., Suzuki M., Maruyama H., Ichikawa T., and Obata F. (2012). LRRK2 phosphorylates tubulin-associated tau but not the free molecule: LRRK2-mediated regulation of the tau-tubulin association and neurite outgrowth. PLoS. One. 7: e30834.

[140] Lin C.H., Tsai P.I., Wu R.M., and Chien C.T. (2010). LRRK2 G2019S mutation induces dendrite degeneration through mislocalization and phosphorylation of tau by recruiting autoactivated GSK3ss. J. Neurosci. 30: 13138-13149.

[141] Anand V.S., Reichling L.J., Lipinski K., Stochaj W., Duan W., Kelleher K., Pungaliya P., Brown E.L., Reinhart P.H., Somberg R. et al. (2009). Investigation of leucine-rich repeat kinase 2 : enzymological properties and novel assays. FEBS J. 276: 466-478.

[142] Reichling L.J. and Riddle S.M. (2009). Leucine-rich repeat kinase 2 mutants I2020T and G2019S exhibit altered kinase inhibitor sensitivity. Biochem. Biophys. Res. Commun. 384: 255-258.

[143] Vetter I.R. and Wittinghofer A. (2001). The guanine nucleotide-binding switch in three dimensions. Science 294: 1299-1304.

[144] Milburn M.V., Tong L., deVos A.M., Brunger A., Yamaizumi Z., Nishimura S., and Kim S.H. (1990). Molecular switch for signal transduction: structural differences between active and inactive forms of protooncogenic ras proteins. Science 247: 939-945. 
[145] Repasky G.A., Chenette E.J., and Der C.J. (2004). Renewing the conspiracy theory debate: does Raf function alone to mediate Ras oncogenesis? Trends in Cell Biology 14: 639-647.

[146] Biosa A., Trancikova A., Civiero L., Glauser L., Bubacco L., Greggio E., and Moore D.J. (2013). GTPase activity regulates kinase activity and cellular phenotypes of Parkinson's disease-associated LRRK2. Hum. Mol. Genet. 22: 1140-1156.

[147] Bourne H.R., Sanders D.A., and Mccormick F. (1991). The Gtpase Superfamily - Conserved Structure and Molecular Mechanism. Nature 349: 117-127.

[148] Civiero L., Vancraenenbroeck R., Belluzzi E., Beilina A., Lobbestael E., Reyniers L., Gao F., Micetic I., De M.M., Bubacco L. et al. (2012). Biochemical characterization of highly purified leucine-rich repeat kinases 1 and 2 demonstrates formation of homodimers. PLoS. One. 7: e43472.

[149] Gotthardt K., Weyand M., Kortholt A., van Haastert P.J., and Wittinghofer A. (2008). Structure of the Roc-COR domain tandem of C. tepidum, a prokaryotic homologue of the human LRRK2 Parkinson kinase. EMBO J. 27: 2239-2249.

[150] James N.G., Digman M.A., Gratton E., Barylko B., Ding X., Albanesi J.P., Goldberg M.S., and Jameson D.M. (2012). Number and Brightness Analysis of LRRK2 Oligomerization in Live Cells. Biophys. J. 102: L41-L43.

[151] Gasper R., Meyer S., Gotthardt K., Sirajuddin M., and Wittinghofer A. (2009). It takes two to tango: regulation of $G$ proteins by dimerization. Nat. Rev. Mol. Cell Biol. 10: 423-429.

[152] Ito G., Okai T., Fujino G., Takeda K., Ichijo H., Katada T., and Iwatsubo T. (2007). GTP binding is essential to the protein kinase activity of LRRK2, a causative gene product for familial Parkinson's disease. Biochemistry 46: 1380-1388.

[153] Guo L., Gandhi P.N., Wang W., Petersen R.B., Wilson-Delfosse A.L., and Chen S.G. (2007). The Parkinson's disease-associated protein, leucine-rich repeat kinase 2 (LRRK2), is an authentic GTPase that stimulates kinase activity. Exp. Cell Res. 313: 3658-3670.

[154] Lewis P.A., Greggio E., Beilina A., Jain S., Baker A., and Cookson M.R. (2007). The R1441C mutation of LRRK2 disrupts GTP hydrolysis. Biochem. Biophys. Res. Commun. 357: 668-671.

[155] Kobe B. and Kajava A.V. (2001). The leucine-rich repeat as a protein recognition motif. Curr. Opin. Struct. Biol. 11: 725-732.

[156] Marin I. (2006). The Parkinson disease gene LRRK2: evolutionary and structural insights. Mol. Biol. Evol. 23: 2423-2433. 
[157] Mata I.F., Wedemeyer W.J., Farrer M.J., Taylor J.P., and Gallo K.A. (2006). LRRK2 in Parkinson's disease: protein domains and functional insights. Trends Neurosci. 29: 286-293.

[158] Nichols R.J., Dzamko N., Morrice N.A., Campbell D.G., Deak M., Ordureau A., Macartney T., Tong Y., Shen J., Prescott A.R. et al. (2010). 14-3-3 binding to LRRK2 is disrupted by multiple Parkinson's disease-associated mutations and regulates cytoplasmic localization. Biochem. J. 430: 393-404.

[159] Greggio E., Taymans J.M., Zhen E.Y., Ryder J., Vancraenenbroeck R., Beilina A., Sun P., Deng J., Jaffe H., Baekelandt V. et al. (2009). The Parkinson's disease kinase LRRK2 autophosphorylates its GTPase domain at multiple sites. Biochem. Biophys. Res. Commun. 389: 449-454.

[160] Iaccarino C., Crosio C., Vitale C., Sanna G., Carri M.T., and Barone P. (2007). Apoptotic mechanisms in mutant LRRK2-mediated cell death. Hum. Mol. Genet. 16: 1319-1326.

[161] van Egmond W.N., Kortholt A., Plak K., Bosgraaf L., Bosgraaf S., Keizer-Gunnink I., and van Haastert P.J. (2008). Intramolecular activation mechanism of the Dictyostelium LRRK2 homolog Roco protein GbpC. J. Biol. Chem. 283: 30412-30420.

[162] Aitken A., Jones D., Soneji Y., and Howell S. (1995). 14-3-3 proteins: biological function and domain structure. Biochem. Soc. Trans. 23: 605-611.

[163] Fu H., Subramanian R.R., and Masters S.C. (2000). 14-3-3 proteins: structure, function, and regulation. Annu. Rev. Pharmacol. Toxicol. 40: 617-647.

[164] Xiao B., Smerdon S.J., Jones D.H., Dodson G.G., Soneji Y., Aitken A., and Gamblin S.J. (1995). Structure of a 14-3-3 protein and implications for coordination of multiple signalling pathways. Nature 376: 188-191.

[165] Deng X., Dzamko N., Prescott A., Davies P., Liu Q., Yang Q., Lee J.D., Patricelli M.P., Nomanbhoy T.K., Alessi D.R. et al. (2011). Characterization of a selective inhibitor of the Parkinson's disease kinase LRRK2. Nat. Chem. Biol. 7: 203-205.

[166] Dzamko N., Deak M., Hentati F., Reith A.D., Prescott A.R., Alessi D.R., and Nichols R.J. (2010). Inhibition of LRRK2 kinase activity leads to dephosphorylation of Ser(910)/Ser(935), disruption of 14-3-3 binding and altered cytoplasmic localization. Biochem. J. 430: 405-413.

[167] Li X., Wang Q.J., Pan N., Lee S., Zhao Y., Chait B.T., and Yue Z. (2011). Phosphorylation-dependent 14-3-3 binding to LRRK2 is impaired by common mutations of familial Parkinson's disease. PLoS. One. 6: e17153.

[168] Greggio E., Zambrano I., Kaganovich A., Beilina A., Taymans J.M., Daniels V., Lewis P., Jain S., Ding J., Syed A. et al. (2008). The Parkinson disease-associated leucine-rich repeat kinase 2 (LRRK2) is a dimer that undergoes intramolecular autophosphorylation. J. Biol. Chem. 283: 16906-16914. 
[169] Jorgensen N.D., Peng Y., Ho C.C., Rideout H.J., Petrey D., Liu P., and Dauer W.T. (2009). The WD40 domain is required for LRRK2 neurotoxicity. PLoS. One. 4: e8463.

[170] Sen S., Webber P.J., and West A.B. (2009). Dependence of leucine-rich repeat kinase 2 (LRRK2) kinase activity on dimerization. J. Biol. Chem. 284: 36346-36356.

[171] Fraser K.B., Moehle M.S., Daher J.P., Webber P.J., Williams J.Y., Stewart C.A., Yacoubian T.A., Cowell R.M., Dokland T., Ye T. et al. (2013). LRRK2 secretion in exosomes is regulated by 14-3-3. Hum. Mol. Genet.

[172] Zhang J., Yang P.L., and Gray N.S. (2009). Targeting cancer with small molecule kinase inhibitors. Nat. Rev. Cancer 9: 28-39.

[173] Mihaly Z., Sztupinszki Z., Surowiak P., and Gyorffy B. (2012). A comprehensive overview of targeted therapy in metastatic renal cell carcinoma. Curr. Cancer Drug Targets. 12: 857-872.

[174] Covy J.P. and Giasson B.I. (2009). Identification of compounds that inhibit the kinase activity of leucine-rich repeat kinase 2. Biochem. Biophys. Res. Commun. 378: 473-477.

[175] Nichols R.J., Dzamko N., Hutti J.E., Cantley L.C., Deak M., Moran J., Bamborough P., Reith A.D., and Alessi D.R. (2009). Substrate specificity and inhibitors of LRRK2, a protein kinase mutated in Parkinson's disease. Biochem. J. 424: 47-60.

[176] Choi H.G., Zhang J., Deng X., Hatcher J.M., Patricelli M.P., Zhao Z., Alessi D.R., and Gray N.S. (2012). Brain Penetrant LRRK2 Inhibitor. ACS Med. Chem. Lett. 3: 658-662.

[177] Estrada A.A., Liu X., Baker-Glenn C., Beresford A., Burdick D.J., Chambers M., Chan B.K., Chen H., Ding X., DiPasquale A.G. et al. (2012). Discovery of highly potent, selective, and brain-penetrable leucine-rich repeat kinase 2 (LRRK2) small molecule inhibitors. J. Med. Chem. 55: 9416-9433.

[178] Chen H., Chan B.K., Drummond J., Estrada A.A., Gunzner-Toste J., Liu X., Liu Y., Moffat J., Shore D., Sweeney Z.K. et al. (2012). Discovery of selective LRRK2 inhibitors guided by computational analysis and molecular modeling. J. Med. Chem. 55: 5536-5545.

[179] Herzig M.C., Kolly C., Persohn E., Theil D., Schweizer T., Hafner T., Stemmelen C., Troxler T.J., Schmid P., Danner S. et al. (2011). LRRK2 protein levels are determined by kinase function and are crucial for kidney and lung homeostasis in mice. Hum. Mol. Genet. 20: 4209-4223.

[180] Ness D., Ren Z., Gardai S., Sharpnack D., Johnson V.J., Brennan R.J., Brigham E.F., and Olaharski A.J. (2013). Leucine-rich repeat kinase 2 (LRRK2)-deficient rats exhibit renal tubule injury and perturbations in metabolic and immunological homeostasis. PLoS. One. 8: e66164. 
[181] Tong Y., Giaime E., Yamaguchi H., Ichimura T., Liu Y., Si H., Cai H., Bonventre J.V., and Shen J. (2012). Loss of leucine-rich repeat kinase 2 causes age-dependent bi-phasic alterations of the autophagy pathway. Mol. Neurodegener. 7: 2.

[182] Berger Z., Smith K.A., and LaVoie M.J. (2010). Membrane localization of LRRK2 is associated with increased formation of the highly active LRRK2 dimer and changes in its phosphorylation. Biochemistry 49: 5511-5523. 